\title{
Errata: Optical fiber-based setup for in vivo measurement of the delayed fluorescence lifetime of oxygen sensors
}

Filippo Piffaretti, Kanappan Santhakumar, Eddy Forte, Hubert E. van den Bergh, and Georges A. Wagnières Biomedical Photonics Group, EPFL, Batiment CH, Station 6, CH-1015 Lausanne, Switzerland

[DOI: $10.1117 / 1.3599043]$

This article [J. Biomed. Opt. 16, 037005 (2011)] was originally published online on 24 March 2011 with an error in the author list. The author listed as "Filippo M. Piffaretti" should have been listed as "Filippo Piffaretti."

The article was corrected online on 24 May 2011. 